\title{
Análise da participação da agropecuária no PIB dos EUA de 1960 a 2001
}

\author{
Ricardo Brugnaro ${ }^{1}$ \\ Carlos José Caetano Bacha
}

Resumo: Este artigo faz uma análise da evolução da participação da agropecuária no PIB dos EUA de 1960 a 2001, dando destaque à análise econométrica das principais variáveis que determinam essa participação. A tendência geral, no período de 1960 a 2001, é a diminuição da participação da agropecuária no PIB. Porém, isto não ocorre de forma contínua, pois de 1971 a 1973 essa participação aumentou. O artigo prova, econometricamente, a quebra de tendência da participação da agropecuária no PIB de 1971 a 1973 e centra sua análise no período de 1973 a 2001. Através de gráficos, observa-se grande crescimento da produção física de cereais e de carnes no período de 1970 a 2001, que se explica pelo grande crescimento da produtividade da agropecuária e dos subsídios governamentais, dado que a tendência da relação de preços recebidos/ preços pagos pela agropecuária foi decrescente nesse período. Baseado em um modelo contábil que explicita as variáveis que determinam a participação da agropecuária no PIB, um modelo econométrico é definido e estimado. As principais variáveis determinando a participação da agropecuária no PIB dos EUA (em ordem decrescente de importância), no período de 1973 a 2001, são a relação de preços recebidos/preços pagos, o valor defasado dessa participação e a produtividade total dos fatores da agropecuária.

\footnotetext{
${ }^{1}$ Mestre em Economia Aplicada pela ESALQ/USP, e-mail: rbrugnaro@yahoo.com,br ${ }^{2}$ Professor Titular da ESALQ/USP, e-mail: cjcbacha@esalq.usp.br
} 
Palavras-chave: PIB, importância da agropecuária, modelo econométrico, EUA

Classificação JEL: Q10, A10.

Abstract: This paper analyses the evolution of agriculture's participation in the US gross domestic product (GDP) from 1960 to 2001. An econometric model is run in order to identify the main variables that determine this participation. From 1960 to 2001, there is a downward trend of agriculture's participation in the US GDP with a break from 1971 to 1973 , in other words, agriculture's participation in the US GDP decreased from 1960 to 1970, increased from 1971 to 1973 and decreased again from 1973 to 2001. The 1971-1973's break in the downward trend of agriculture's participation is econometrically proved. Dataset organized in graphs show grain and meat production steadily enlarged from 1970 to 2001, what is closely related to the productivity increase and federal grants to agriculture, despite the ratio of received/paid prices decreased during this 31 years. An accounting model is presented to show the main variables that determine agriculture's participation in a country's GDP and an econometric model is derived from this accounting model. Running this econometric model with 1973-2001's US dataset, the following variables are the most important to determine the participation of agriculture in the US GDP: received/paid prices ratio, lagged value of agriculture's participation in the GDP, and total factor productivity of the agriculture.

Key words: GDP, agriculture importance, econometric model, The USA

\section{Introdução}

A pesquisa em economia agrícola revela a tendência declinante da participação da agropecuária na composição do PIB (produto interno bruto) da maioria dos países ao longo do tempo. Não diferente desta tendência, os EUA apresentam este comportamento - embora com algumas oscilações em torno da tendência - desde o fim do século XVIII (SCHULTZ, 1951). Outros países desenvolvidos, como Japão, 
Inglaterra, França, Alemanha, Austrália e Canadá, também apresentam este comportamento declinante (Figura 1).

Figura 1 - Participação da agropecuária no PIB de alguns países desenvolvidos -1960 a $2003^{3}$
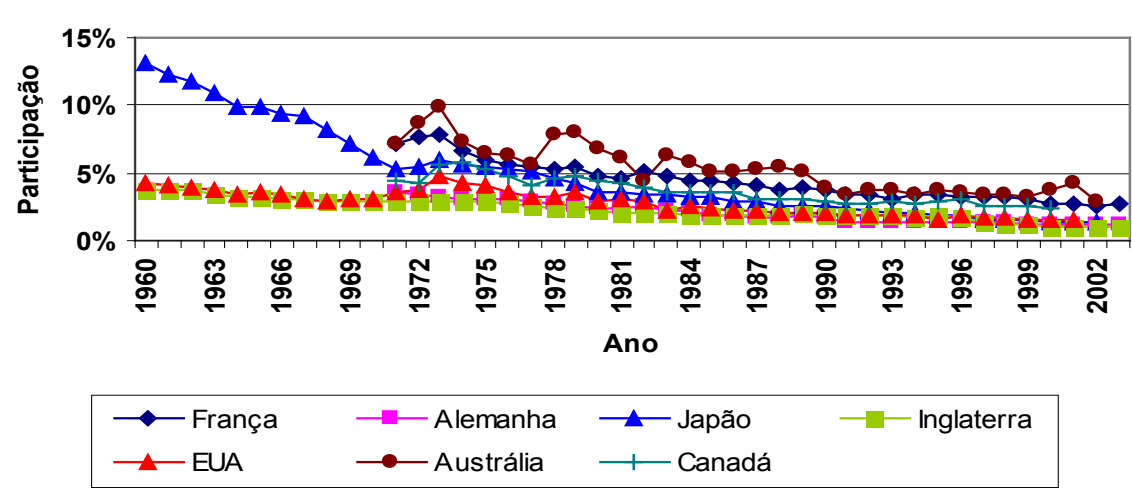

Fonte: World Bank $(2000,2005)$

A agropecuária norte-americana tem pouca importância relativa na composição do PIB (1,6\% em 2001, de acordo com o World Bank, 2005), porém, este setor dinamiza os outros setores da economia (setores industrial e de serviços), sendo de extrema importância para o processo produtivo da economia (GUILHOTO, 2004), assim como pela geração de emprego (responsável por aproximadamente 2,5\% do emprego dos EUA) e fornecimento de alimentos (em termos estratégicos). Esses fatores são fundamentais para defender o apoio governamental à produção agropecuária nos EUA.

\section{Objetivo}

O objetivo deste artigo é analisar a evolução da participação da agropecuária no PIB dos EUA e avaliar, econometricamente, as principais variáveis que determinam essa participação.

Este artigo está dividido em 7 seções, incluindo a introdução e o

${ }^{3}$ De acordo com a disponibilidade de dados, a participação da agropecuária no PIB é apresentada para períodos menores. 
objetivo. A seção 3 apresenta uma revisão bibliográfica sobre o desenvolvimento econômico e a participação da agropecuária no PIB. A seção 4 apresenta as evidências da importância decrescente da agropecuária no PIB e no emprego dos EUA. A seção 5 expõe a metodologia e os dados utilizados no presente trabalho, e as seções 6 e 7 trazem, respectivamente, os resultados dos modelos econométricos estimados e as considerações finais.

\section{Revisão bibliográfica}

A literatura relacionada ao objetivo deste artigo pode ser organizada em três grupos interligados entre si: primeiro, os trabalhos que relacionam a participação decrescente do PIB na agropecuária ao estilo de desenvolvimento urbano-industrial adotado pelos países; segundo, os trabalhos que ressaltam a dimensão da participação da agropecuária no PIB dos EUA; e terceiro, os trabalhos que ressaltam a importância da agropecuária para os EUA e suas fontes de crescimento, apesar de sua pequena importância no PIB, e que procuram justificativas para os subsídios governamentais dados a esse setor.

\subsection{Desenvolvimento urbano-industrial e a participação decrescente da agropecuária no PIB}

A maioria dos autores relata a tendência declinante da participação da agropecuária na composição do PIB de grande parte dos países do mundo, como por exemplo, Schultz (1951), Ahumada (1967), Araújo (1975), Araújo e Schuh (1988), Syrquin ${ }^{4}$ (1988), Stern (1994), Alexandratos (1999), Gollin et al. (2000) e Guilhoto (2004), associando essa tendência ao processo de desenvolvimento econômico.

O modelo de desenvolvimento adotado pela sociedade, que consiste na busca por benefícios sociais (acesso à educação, saúde, lazer, entre outros benefícios sociais) e consumo em massa, associa-se fortemente ao desenvolvimento urbano-industrial (ALVES, 2000).

${ }^{4}$ SYRQUIN, M. Patterns of structural change. In: CHENERY, H.; SRINIVASAN, T.N. Handbook of development economics. Amsterdan: Elsevier Science Publishers, 1988. v. 1. Chapter 7, p. 203 a 273. 
Ahumada (1967), Araújo (1975) e Araújo e Schuh (1988), ao descreverem características do processo de desenvolvimento da sociedade, relatam a ocorrência de modificações estruturais na produção e na renda, com a redução da participação do setor agropecuário na formação da renda (produto), concomitantemente ao crescimento da participação do setor industrial e de serviços na composição da renda. Araújo (1975) também relata a perda da importância relativa da agropecuária como geradora de emprego em virtude do alto grau de urbanização que caracteriza o processo de desenvolvimento econômico.

Araújo (1975) ressalta que, com o desenvolvimento econômico (e o conseqüente crescimento da renda), aumenta-se a demanda por bens manufaturados e serviços especializados. Estes setores aumentam sua participação na composição da renda em detrimento da agropecuária, já que os setores secundário e terciário crescem mais rapidamente que o setor primário (no qual se inclui a agropecuária).

Araújo e Schuh (1988) comentam que o processo de desenvolvimento apresenta um comportamento paradoxal. O desenvolvimento urbano-industrial ocorre amparado nas transferências dos excedentes gerados pelo setor agropecuário para os setores secundário e terciário, fazendo com que estes aumentem sua importância relativa na geração da renda e do emprego em detrimento do setor agropecuário. Desenvolvidos os setores urbanos da economia, deve-se reforçar os investimentos nas atividades agropecuárias para estas garantirem o fornecimento de alimentos para a população, revelando que embora a agropecuária perca participação na geração da renda e do emprego, ela não deixa de ser importante, segundo Schuh (1997), uma vez que sua competitividade permite ofertar alimentos, que são bens salário, a preços menores, levando à melhor distribuição da renda e ao aumento da demanda por bens e serviços de outros setores.

Syrquin 1988, apud Alves (2000), comenta que mudanças técnicas na agricultura e/ou aumento no preço relativo do trabalho induzem à mecanização e ao uso de insumos externos à agropecuária (combustíveis, fertilizantes, bens de capital), o que faz com que reduza o valor adicionado do setor agropecuário. Este mesmo autor revela a redução da participação da agropecuária na renda e no emprego em um estudo realizado para 97 países no período de 1950 a 1983. 
Stern (1994) aponta a perda nos preços relativos (preços agropecuários / preços industriais) como a principal causa da redução da participação da agropecuária no PIB total de um país.

Gollin et al. (2000) relata que o desenvolvimento econômico-social ocorre com a liberação de mão-de-obra das atividades agropecuárias para as atividades urbano-industriais, gerando dessa forma rendas (produto) não oriundas da agropecuária, reduzindo a participação desta no total da renda gerada. Os autores comentam a necessidade de ganhos de produtividade na agropecuária para que essa continue fornecendo alimentos em abundância para a população que não está mais trabalhando nas atividades agropecuárias, concordando com Araújo e Schuh (1975), quando afirmam que outra característica importante do desenvolvimento é o crescimento da produtividade do trabalho e a diminuição da diferença desta entre os diferentes setores da economia. Isto implica o crescimento mais acelerado da produtividade do trabalho na agropecuária se comparado aos outros setores, pois a renda gerada por cada trabalhador na agropecuária é inferior à dos outros setores (WORLD BANK, 2005).

Guilhoto (2004), utilizando dados cross-section e recentes, também mostra que países com renda per capita mais elevada tendem a apresentar menor participação da agropecuária no PIB.

Alexandratos (1999) relata que os países subdesenvolvidos estão assumindo a produção de alimentos para a população dos países desenvolvidos, tornando a questão da segurança alimentar em insegurança (“food insecurity”). Em virtude da falta de competitividade na produção agropecuária dos países mais ricos, esta atividade reduz cada vez mais em certos países, mesmo com altos subsídios governamentais, contribuindo para a redução da participação do setor na composição do PIB desses países.

No caso do Brasil, que se comportou atipicamente em relação à tendência da maioria dos países dos anos 90 e começo dos anos 2000, o crescimento da participação da agropecuária no PIB nesses anos, segundo Bacha e Rocha (1998), foi devido a três fatores principais: (1) a melhora dos preços relativos agropecuários/ preços industriais; (2) a melhora da relação de preços recebidos/ preços pagos pela agropecuária; e (3) o aumento da quantidade física produzida na agropecuária advinda do aumento da produtividade. Barros (1999) relata que o cres- 
cimento da produção agropecuária brasileira nos últimos anos é devido, principalmente, aos ganhos de produtividade dos fatores produtivos (proporcionados pelas inovações tecnológicas) e pelo crescimento do estoque de capital (principalmente de tratores) e do uso de insumos promovidos pelo grande investimento realizado na agropecuária brasileira até 1986, tanto na forma de pesquisa e extensão rural, como na concessão de crédito rural subsidiado. Este crescimento de produtividade é confirmado por Gasques et al (2004), que evidenciam o grande crescimento da produtividade total dos fatores (PTF) a partir de 1994, calculada através do índice de Tornqvist. Bonelli $(2001,2005)$ confirma que o crescimento da participação da agropecuária no PIB do Brasil é reflexo dos elevados ganhos de produtividade que o setor apresenta desde o início da década de 1990, além de ressaltar o fraco desempenho do setor industrial no que diz respeito à PTF (produtividade total dos fatores), neste mesmo período. Rossi Jr \& Ferreira (1999) evidenciam decréscimo na PTF industrial para o período de 1985 a 1990, e reduzido crescimento para o período de 1990 a 1997, confirmando a tendência apresentada por Bonelli (2001).

\subsection{A participação da agropecuária no PIB dos EUA}

Schultz (1951) relata a tendência declinante da participação da agropecuária na composição do produto interno bruto para a Inglaterra e EUA de 1800 a 1950. Com o crescimento da renda per capita, as pessoas passam a demandar outros tipos de bens além dos alimentos, uma vez que a quantidade consumida de alimentos já está em um patamar desejado pela população que possui um nível elevado de renda (nível de renda que permita a satisfação das necessidades alimentares). Assim, como os outros setores da economia crescem mais que a agropecuária, esta tende a reduzir sua participação na composição do PIB. O crescimento de outros setores da economia é possibilitado pela liberação de mão-de-obra do setor agropecuário para esses setores em virtude do crescimento da produtividade do trabalho na agropecuária, proporcionado por inovações tecnológicas.

O agronegócio, tradução do termo inglês agribusiness, se refere ao conjunto de atividades vinculadas com a agropecuária, incluindo 
a atividade agropecuária e outros três segmentos: o segmento de insumos para a agropecuária, o segmento de processamento de produtos agropecuários e o segmento de distribuição dos produtos agropecuários e agroindustriais (BACHA, 2004). Embora o processo de desenvolvimento urbano-industrial leve à redução da importância da agropecuária na economia, segundo Furtuoso e Guilhoto (2003) e Guilhoto (2004), o agronegócio tem maior importância econômica que somente a agropecuária. Nos EUA, a agropecuária representou aproximadamente 1,6\% do PIB em 1998, enquanto o agronegócio representou $8,1 \%$ do PIB.

\subsection{A importância da agropecuária para os EUA}

Além da importância econômica da agropecuária para os EUA, Regunaga (2004) salienta a importância social, ambiental e estratégica da agropecuária para este país. Este setor é responsável por cerca de 2,5\% do emprego nos EUA [mais de 50\% superior à sua importância em termos da geração do PIB - valores confirmados pelo UNITED STATES DEPARTMENT OF AGRICULTURE - (USDA), 2006] e pela manutenção de parte da população no meio rural. A agropecuária também é importante em termos estratégicos, pois garante alimentação para a população. Dadas estas importâncias da agropecuária norte-americana, justificam-se os elevados subsídios governamentais à atividade, contribuindo para a não liberalização do comércio internacional de commodities agrícolas.

Westcott e Price (2001) salientaram a importância dos programas de financiamentos (empréstimos) subsidiados do governo dos EUA a fim de garantir um nível de renda mais elevado aos produtores agropecuários, e dessa forma dar continuidade à produção. Estes programas são fundamentais para que a agropecuária não reduza ainda mais sua contribuição para o PIB do país e, além disso, continue gerando empregos e produzindo alimentos. Os autores também relataram o papel do USDA no financiamento e na coordenação da pesquisa pública e privada para geração de tecnologia, contribuindo para o crescimento da produtividade agropecuária.

O Serviço de Pesquisa Econômica (ERS) do Departamento de Agricultura dos EUA (USDA) publica relatórios anuais, de 1995 a 2006, 
sobre o desempenho da agropecuária dos EUA em relação à renda e finanças agrícolas. Os temas abordados são: a renda agrícola e familiar, a lucratividade das atividades agropecuárias, os gastos feitos pelo governo com a agropecuária, os gastos dos agricultores com a produção e a evolução de seus ativos e dívidas.

O ERS, ao analisar a renda agrícola, preocupa-se mais em decompor sua origem segundo o tipo de atividade agropecuária (agrícola, pecuária e silvicultura), os tipos de gastos incorridos (com fertilizantes, sementes, pesticidas, eletricidade, por exemplo) e a importância das transferências públicas. Pouca atenção é dada à análise da participação da agropecuária na formação do PIB norte-americano.

Uma série de trabalhos, tanto sobre os EUA quanto a respeito de outros países desenvolvidos e em desenvolvimento, tem se preocupado na última década em analisar a evolução da produtividade da agropecuária, os fatores determinantes do crescimento da produtividade e de que maneira a melhoria de produtividade tem permitido à agropecuária crescer, apesar de haver queda de preços relativos em desfavor da agropecuária. Destacam-se, nessa linha, o trabalho de Ruttan (2002), analisando essas questões para vários países, e o de Fuglie et al (2007) que analisa o caso dos EUA.

Fuglie et al (2007) analisaram a evolução da produtividade total dos fatores (PTF) na agropecuária norte-americana de 1948 a 2004. Nesse período, a PTF cresceu à taxa média de 1,8\% ao ano. Isto permitiu, por exemplo, que “... cada fazendeiro em 2000 produzisse em média 12 vezes mais produto agrícola por hora trabalhada do que fazia em 1950. O desenvolvimento de nova tecnologia foi o fator primário dessa melhoria” (Fuglie et al, 2007, p. 1). Entre essas melhorias se situam a melhoria de qualidade de maquinaria e insumos químicos, bem como o uso de biotecnologia. Os mesmos autores mostram que, a partir de início da década de 1970, os preços em geral cresceram mais do que os preços agrícolas e esse gap foi compensado, pela agropecuária, por um grande crescimento da produtividade agrícola.

Avaliando a literatura apresentada até agora, verificam-se muitos trabalhos analisando os motivos e as variáveis responsáveis pelo comportamento da participação da agropecuária no PIB dos países. Porém, nenhum trabalho estimou um modelo econométrico para quantificar a 
importância das variáveis ressaltadas na determinação do PIB para o caso da economia dos EUA, que é o propósito deste artigo.

\section{As evidências da importância decrescente da agropecuária no PIB e no emprego dos EUA}

Como já mencionado, a participação da agropecuária no PIB dos EUA tem apresentado comportamento decrescente, seguindo o padrão mundial dado pelas teorias de desenvolvimento. Para se ter uma idéia, a agropecuária foi responsável por quase $40 \%$ do PIB dos EUA em 1799, passando para cerca de $32 \%$ em meados do século XIX, $21 \%$ em 1900, $13 \%$ no final da década de 1930, 3,5\% na década de 1970, e apenas 1,6\% em 2000 (Figura 2).

A agropecuária dos EUA não perdeu importância relativa apenas na composição do PIB, mas também em termos de geração de emprego. Em 1805, a agropecuária era responsável por 70\% dos postos de trabalho dos EUA, passando a representar aproximadamente 2,4\% nos anos atuais (Figura 3). Porém, ao verificar uma participação de 2,4\% no emprego e apenas $1,6 \%$ do PIB dos EUA, conclui-se que a agropecuária tem importante função social, gerando emprego acima de sua participação na renda total do país.

Figura 2 - Participação da agropecuária no PIB do EUA - anos selecionados

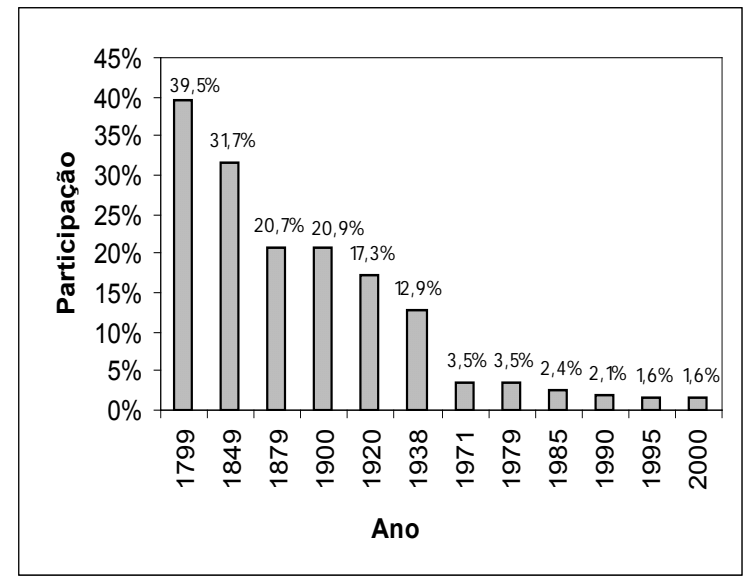

Fonte: Schultz (1951) e World Bank (2005) 
Figura 3 - Participação da agropecuária no emprego dos EUA - anos selecionados

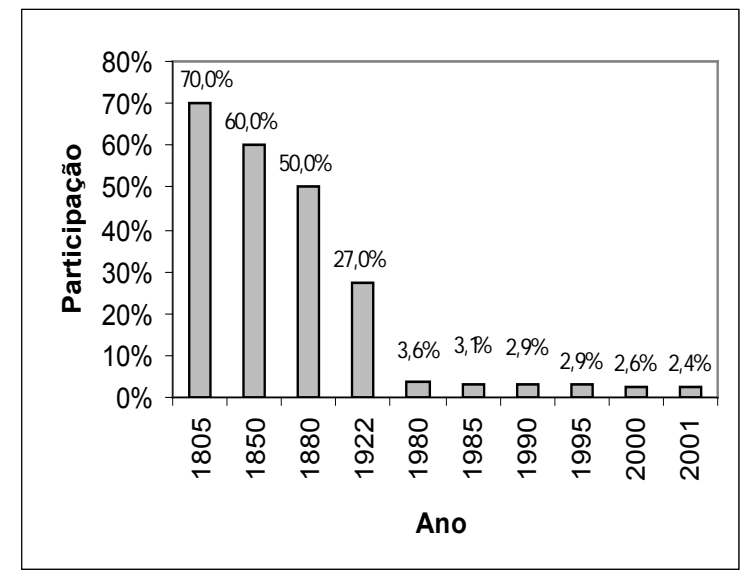

Fonte: Schultz (1951) e World Bank (2005)

Pela sua importância na geração de empregos e por outros motivos, o governo tem dado grande atenção ao setor, destinando representativo volume de recursos para pesquisa e concessão de subsídios ao produtor rural a fim de dar continuidade ao processo produtivo.

\section{Metodologia e dados utilizados}

\subsection{Modelo de determinação da participação do setor agropecuário no PIB}

Esta seção expõe o modelo contábil de Bacha e Rocha (1998) sobre a determinação da participação da agropecuária no PIB, derivando, a partir dele, um modelo econométrico e discutindo os dados viáveis para estimá-lo. O modelo também já foi utilizado e estimado econometricamente por Brugnaro e Bacha (2006) para analisar a participação da agropecuária no PIB do Brasil.

Bacha e Rocha (1998) definiram as seguintes variáveis:

$\mathbf{V A}_{\mathrm{A}}=\quad$ valor adicionado pelo setor agropecuário;

$\mathbf{V A}_{\mathrm{I}}=\quad$ valor adicionado pelo setor não-agropecuário;

$\mathbf{P}_{\mathrm{A}}=$ preço médio dos produtos do setor agropecuário;

$\mathbf{P}_{\mathbf{I}}=$ preço médio dos bens e serviços do setor não-agropecuário; 
$\mathbf{P}_{\mathrm{A}}{ }^{\mathrm{I}}=$ preço médio dos produtos agropecuários usados como insumos no setor não-agropecuário;

$\mathbf{P}_{\mathbf{I}}^{\mathbf{A}}=$ preço médio dos bens e serviços não-agropecuários usados como insumos no setor agropecuário;

$\mathbf{I}_{\mathrm{I}}^{\mathrm{A}}=$ quantidade física de insumos não-agropecuários usados no setor agropecuário;

$\mathbf{I}_{\mathbf{A}}{ }^{\mathbf{A}}=$ quantidade física de insumos agropecuários usados no setor agropecuário;

$\mathbf{I}_{\mathbf{I}}^{\mathbf{I}}=$ quantidade física de insumos não-agropecuários usados no setor não-agropecuário;

$\mathbf{I}_{\mathbf{A}}{ }^{\mathbf{I}}=$ quantidade física de insumos agropecuários usados no setor não-agropecuário;

$\mathbf{Q}_{\mathrm{A}}=$ quantidade física produzida no setor agropecuário;

$\mathbf{Q}_{\mathbf{I}}=$ quantidade física produzida no setor não-agropecuário.

Portanto, o subscrito é o setor que produz e o sobrescrito é o setor que utiliza. A é setor agropecuário e I é o setor não-agropecuário.

O modelo de Bacha e Rocha (1998) tem quatro equações básicas, que são:

$$
P_{\text {agr }}=\frac{V A_{A}}{V A_{l}+V A_{A}} \quad \text { ou } \quad P_{\text {agr }}=\frac{1}{1+\frac{V A_{l}}{V A_{A}}}
$$

onde $\mathrm{P}_{\mathrm{agr}}$ é a participação da agropecuária no PIB.

Da equação (1) tem-se que o aumento de $\frac{V A_{A}}{V A_{l}}$ faz aumentar $\mathrm{P}_{\mathrm{agr}}$. Para determinar as variáveis que afetam $\frac{V A_{A}}{V A_{l}}$, considere que:

$$
\begin{aligned}
& V A_{A}=P_{A} \cdot Q_{A}-P_{A} \cdot I_{A}^{A}-P_{I}^{A} \cdot I_{I}^{A} \\
& V A_{I}=P_{I} \cdot Q_{I}-P_{A}^{\prime} \cdot I_{A}^{\prime}-P_{I} \cdot I_{I}^{\prime}
\end{aligned}
$$

Dividindo (2) por (3), e da expressão resultante dividindo o numerador e o denominador por $\mathrm{P}_{\mathrm{A}}$ e procedendo a ajustes matemáticos, tem-se: 


$$
\frac{V A_{A}}{V A_{1}}=\frac{\left(Q_{A}-I_{A}^{A}\right)-\frac{P_{1}^{A}}{P_{A}} \cdot I_{l}^{A}}{\frac{P_{1}}{P_{A}} \cdot\left(Q_{1}-I_{1}^{\prime}\right)-\frac{P_{A}^{\prime}}{P_{A}} \cdot I_{A}^{\prime}}
$$

A expressão (4), em seu numerador, revela que um aumento na produtividade física do setor agropecuário [aumento de $\left(Q_{A}-I_{A}^{A}\right)$ ], em condições coeteris paribus, leva ao aumento de $\frac{V A_{A}}{V A_{t}}$, o que, pela expressão (1), leva ao aumento da participação do setor agropecuário no PIB. Ainda em seu numerador, a expressão (4) mostra que um aumento de $\frac{P_{A}}{P_{I}^{A}}$ (valor adicionado unitário no setor agropecuário), em condições coeteris paribus, eleva $\frac{V A_{A}}{V A_{I}}$, gerando um aumento da participação do setor agropecuário no PIB.

A expressão (4), em seu denominador, coloca que a redução de $\frac{P_{I}}{P_{A}}$, ou o aumento de $\frac{P_{A}}{P_{I}}$ (relação de preços agropecuários e nãoagropecuários), em condições coeteris paribus, aumenta $\frac{V A_{A}}{V A_{l}}$, o que também eleva a participação do setor agropecuário no PIB.

Os três elementos acima evidenciados foram ressaltados por Bacha e Rocha (1998). Cabe ressaltar, também, que o aumento da produtividade industrial [aumento de $\left(Q_{l}-I_{l}^{l}\right)$ ], em condições coeteris paribus, reduz a relação $\frac{V A_{A}}{V A_{l}}$, reduzindo a participação da agropecuária no PIB. Essas conclusões permitem estimar a equação (4) através da seguinte fórmula:

$$
\mathrm{P}_{\mathrm{agr}}=\frac{V A_{A}}{V A_{1}+V A_{A}}=f\left[\left(Q_{A}-l_{A}^{A}\right) \cdot \frac{P_{A}}{P_{1}} \cdot \frac{P_{1}^{A}}{P_{A}},\left(Q_{1}-1\right)\right]
$$


sendo que

$$
\begin{aligned}
& \left(Q_{A}-I_{A}^{A}\right) \uparrow \Rightarrow P_{a g r} \uparrow \quad ; \quad \frac{P_{I}^{A} \uparrow \Rightarrow P_{a g r} \downarrow}{P_{A}} ; \\
& \left(Q_{I}-I_{I}^{I}\right) \uparrow \Rightarrow P_{a g r} \downarrow \\
& \text { e }
\end{aligned} \quad \begin{aligned}
& \frac{P_{A}}{P_{I}} \uparrow \Rightarrow P_{a g r} \uparrow
\end{aligned}
$$

\subsection{Dados utilizados}

Para estimar a equação (5) são utilizados dados secundários. Os dados de participação do setor agropecuário no PIB total são do World Bank $(2000,2005)$. Os preços $P_{A}, P_{I}$ e $P_{I}^{A}$ são mensurados na forma de índices. As produtividades da agropecuária e da indústria (considerada como proxy da produtividade do setor não agropecuário) também são mensuradas na forma de índices. Os índices de preços recebidos e pagos pela agropecuária e o índice de produtividade total dos fatores no setor agropecuário são do Departamento de Agricultura dos EUA (USDA). Os índices de preços industriais e agropecuários e o índice de produtividade total dos fatores na indústria são do Bureau of Labor Statistics (BLS).

Para caracterização da agropecuária dos EUA foram apresentados dados referentes à produção e produtividade dos cereais e área com irrigação fornecidos pelo World Bank, subsídios à agropecuária fornecidos pela Organização para Cooperação Econômica e Desenvolvimento (OCDE), além da produção de carnes e produtividade total dos fatores da pecuária e da agropecuária e a produtividade do trabalho na agropecuária fornecidos pelo USDA.

\section{Resultados}

Esta seção analisa, através de gráficos, o comportamento de algumas variáveis determinantes do valor do produto interno bruto da agropecuária e/ou de sua participação no PIB total dos EUA. Essas variáveis foram definidas a partir da literatura consultada e baseado no modelo de Bacha e Rocha (1998) e são analisadas para o período de 1970 a 2001. Em seguida, o modelo econométrico definido no item 
5.1 (equação 5) é estimado de várias formas para determinar a importância das variáveis selecionadas na determinação da participação da agropecuária no PIB dos EUA.

\subsection{Preços relativos}

- Preços agropecuários versus preços industriais

A Figura 4 mostra a evolução dos índices de preços agropecuários, industriais e a relação de preços agropecuários/preços industriais. Embora existam certas oscilações em torno da tendência, verifica-se claramente o crescimento mais acelerado do índice de preços industriais (índice de preços industriais utilizado como proxy para preços não-agropecuários), fazendo com que a razão de preços agropecuários/preços industriais se reduza em aproximadamente $40 \%$ no período de 1970 a 2001, contribuindo para a redução da participação da agropecuária no PIB dos EUA.

Os preços agropecuários cresceram a uma taxa geométrica ${ }^{5}$ de $2 \%$ ao ano no período de 1970 a 2001, enquanto que o índice de preços industriais cresceu, no mesmo período, a uma taxa de $4,3 \%$ ao ano, implicando uma redução de $2,2 \%$ ao ano na relação de troca preços agropecuários/ preços industriais.

\section{- Preços recebidos versus preços pagos}

Avaliando a Figura 5, verifica-se que a relação de preços recebidos/ preços pagos pela agropecuária dos EUA também contribuiu para a redução da participação da agropecuária no PIB. Esta relação reduziu-se a uma taxa geométrica anual de $2,3 \%$, perfazendo um total de queda de $45 \%$ no período de 1970 a 2001 . Isto ocorreu porque os preços recebidos cresceram, no referido período, a uma taxa geométrica de 2,1\% ao ano, enquanto os preços pagos cresceram a uma intensidade muito maior: $4,5 \%$ ao ano.

${ }^{5}$ A taxa geométrica de crescimento é definida como: TGC $=\mathbf{e}^{\mathbf{b}}-\mathbf{1}$, onde $\mathbf{b}$ é o coeficiente da regressão $\mathbf{Y}=\mathbf{a}+\mathbf{b} \ln \mathbf{t}$ (em que $\mathrm{Y}$ é a variável avaliada e t é o tempo). 
Figura 4 - Evolução dos índices de preços agropecuários e industriais nos EUA (Base $100=1970)$

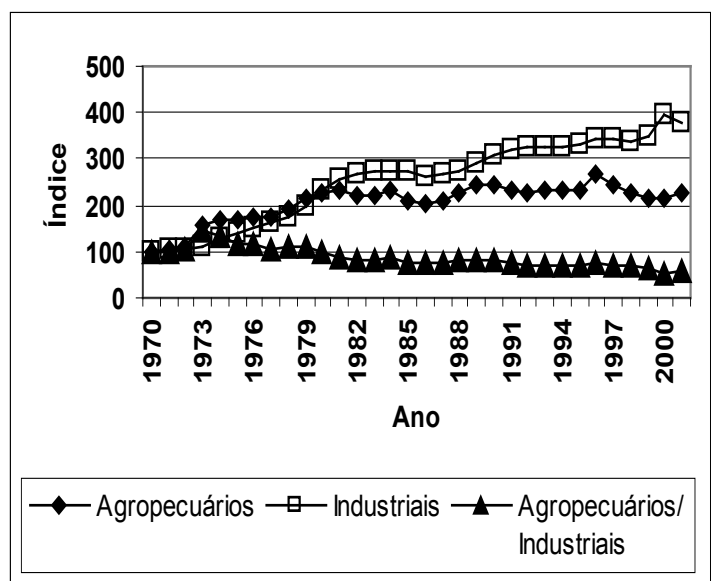

Fonte: BLS (2006)

Figura 5 - Evolução dos índices de preços recebidos e pagos pela agropecuária dos EUA (Base $100=1970$ )

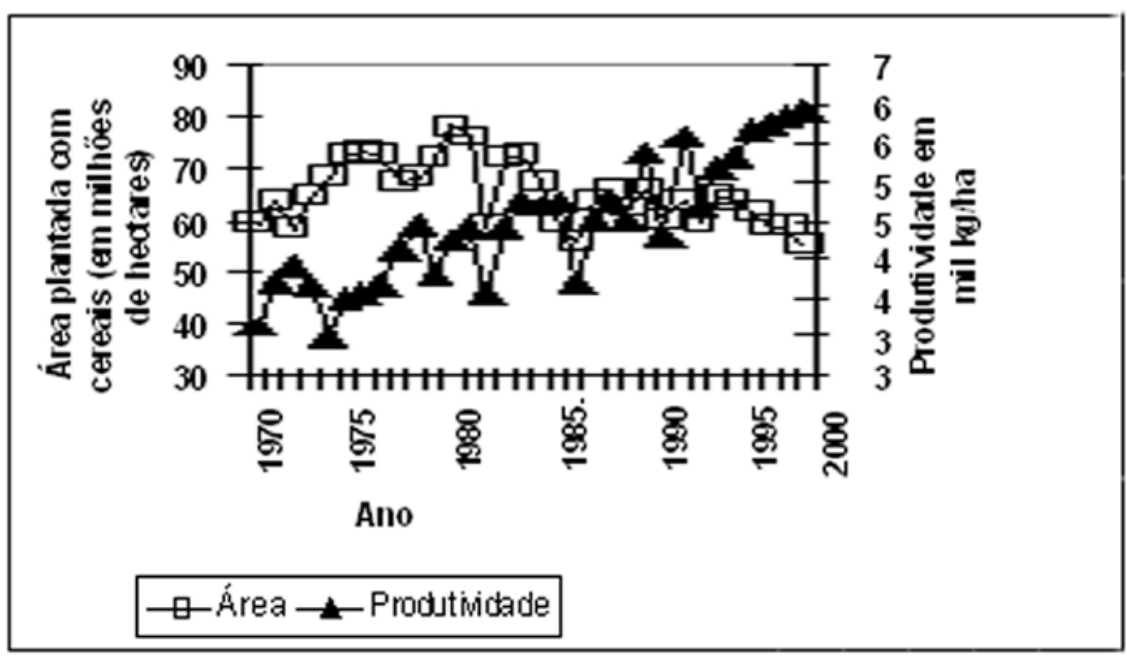

Fonte: USDA (2006) 


\subsection{Produção e índices de produtividade da agropecuária}

\section{- Produção agrícola}

A produção de cereais dos EUA apresentou grande crescimento no período de 1970 a 2001, passando de menos de 187 milhões de toneladas para 325,5 milhões de toneladas, respectivamente. Este crescimento ocorreu com grandes oscilações, principalmente na década de 1980 (Figura 6). Avaliando o período como um todo, o crescimento ocorreu a uma taxa geométrica de 1,3\% ao ano.

A área plantada com cereais nos EUA cresceu de 1970 até meados da década de 1980, reduzindo-se a partir de então. Em 2001, a área plantada era inferior a de 1970 (Figura 7). Para o período de 1970 a 2001 como um todo, a área plantada com cereais reduziu-se a uma taxa geométrica de $0,42 \%$ a.a.. Assim, conclui-se que o crescimento na produção de cereais, no mencionado período, ocorreu com grande crescimento da produtividade por hectare (ver Figura 7). A produtividade média passou de $3.150 \mathrm{~kg}$ por hectare em 1970 para $5.890 \mathrm{~kg}$ por hectare em 2001, com uma taxa geométrica de crescimento de $1,74 \%$ ao ano.

O crescimento em produtividade por hectare, verificado no período de 1970 a 2001, ocorreu devido a grandes investimentos em pesquisa e em mecanização das atividades. O crescimento da área com sistemas de irrigação ilustra, em parte, os investimentos em capital ocorridos na produção agrícola nos EUA. Em 1970, havia 16 milhões de hectares irrigados nos EUA, área que passou para 22,5 milhões de hectares em 2001 (Figura 8), ao mesmo tempo em que houve redução na área plantada com cereais, elevando dessa forma a participação da área plantada dotada de sistemas de irrigação.

A produção agropecuária dos EUA tem grande apoio governamental, desde pesquisa (coordenação e financiamento), até seguro, de preço e produtividade. Assim, a produção agropecuária passa a ter menor risco econômico, amparando-se em crescentes subsídios, que atingiu nos anos de 1998 a 2001 um patamar bastante superior ao verificado nos anos de 1990 a 1997. O pico alcançado foi de US\$ 60,1 bilhões (a preços de 2001) em 1999, como pode ser visualizado na Figura 9. Este crescimento verificado na concessão de subsídios ocorre para manter a viabilidade econômica da atividade agropecuária nos EUA. 
Figura 6 - Evolução da produção de cereais dos EUA - 1970 a 2001

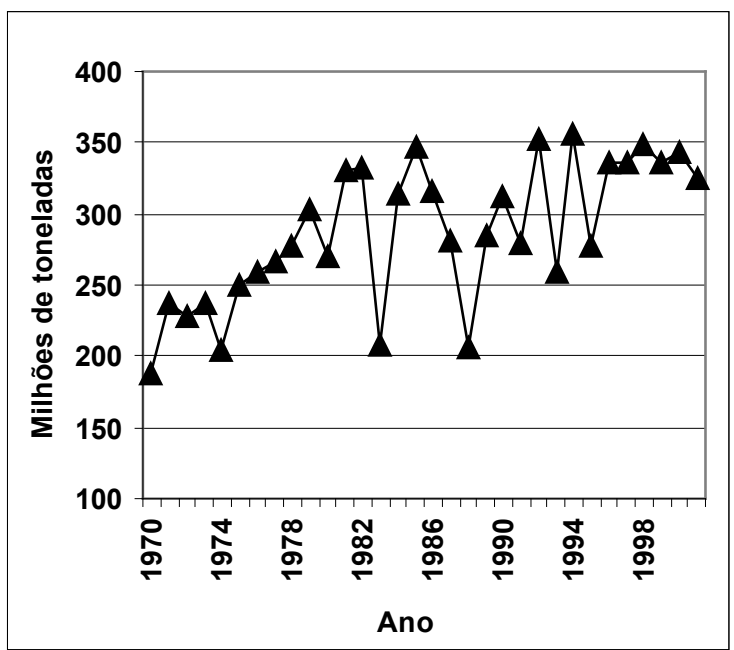

Fonte: World Bank (2005)

Figura 7 - Evolução da área plantada e da produtividade dos cereais nos EUA de 1970 a 2001

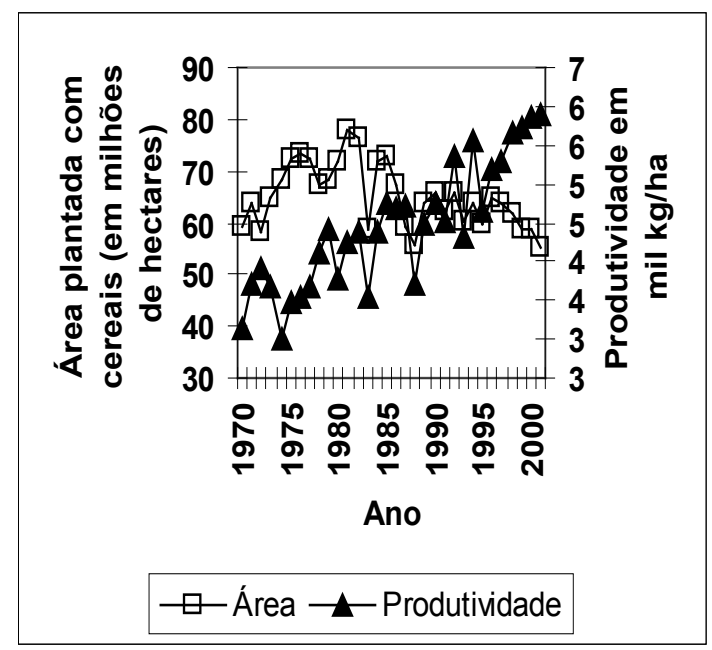

Fonte: World Bank (2005) 
Figura 8 - Evolução da área com Irrigação nos EUA para o período de 1970 a 2001

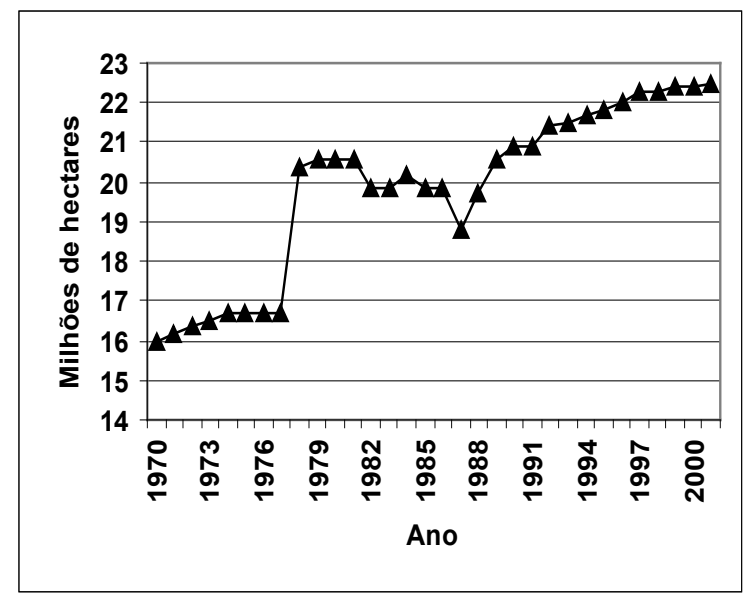

Fonte: World Bank (2005)

Figura 9 - Evolução dos subsídios governamentais à agropecuária dos EUA para o período de 1986 a 2001 (a preços de 2001)

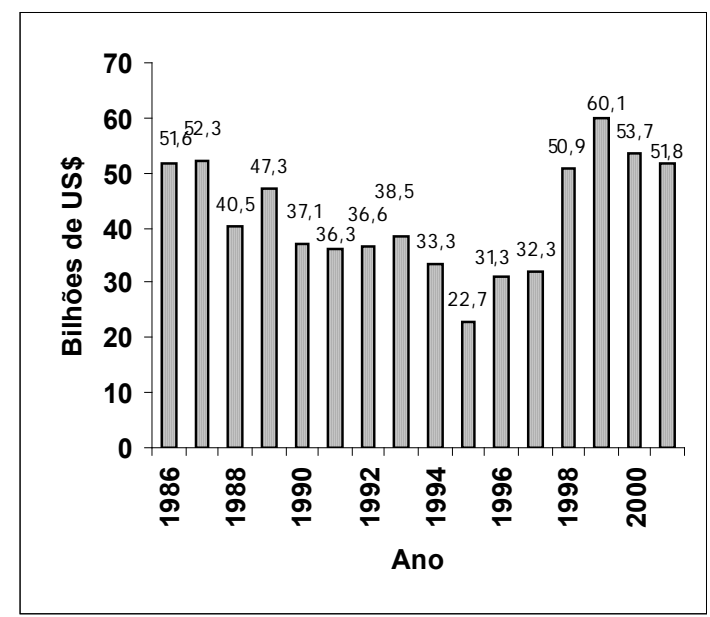

Fonte: OCDE (2006) 


\section{- Produção de carnes}

Analisando a produção de carnes dos EUA (Figura 10), percebe-se o crescimento para as carnes bovina, suína e de aves (as principais carnes produzidas nos EUA). A produção de carne bovina apresentou uma taxa geométrica de crescimento de $0,48 \%$ ao ano no período de 1970 a 2001, passando de 9,75 milhões de toneladas em 1970 para 11,85 milhões de toneladas em 2001. Ao mesmo tempo, a produção de carnes suínas apresentou crescimento geométrico de 1,31\% ao ano, elevando sua produção de 6 milhões de toneladas em 1970 para 8,7 milhões de toneladas em 2001. Altamente expressivo foi o crescimento da produção de carne de aves nos EUA, passando de 4,2 milhões de toneladas em 1970 para mais de 17 milhões de toneladas em 2001, implicando uma taxa geométrica de crescimento de 5,02\% ao ano no período compreendido entre 1970 e 2001.

Para se ter uma idéia da evolução da produção de carnes dos EUA avaliadas para as carnes bovina, suína e de aves conjuntamente, o volume produzido passa de menos de 20 milhões de toneladas em 1970 para mais de 37 milhões de toneladas em 2001, equivalente à taxa geométrica de crescimento anual de 2,15\%.

Figura 10 - Evolução da produção de carnes nos EUA no período de 1970 a 2001

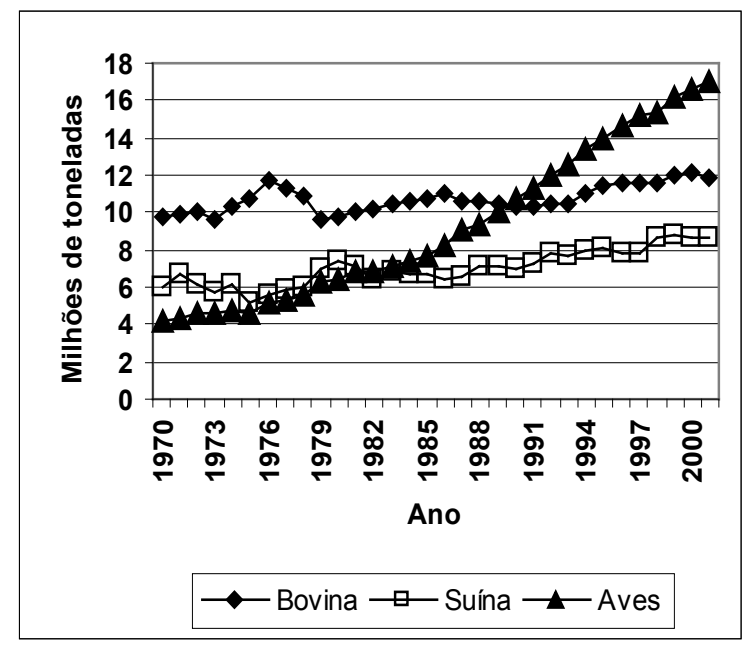

Fonte: USDA (2006) 
Figura 11 - Evolução da produtividade total dos fatores na pecuária dos EUA para o período de 1970 a 2001 (base $100=1970$ )

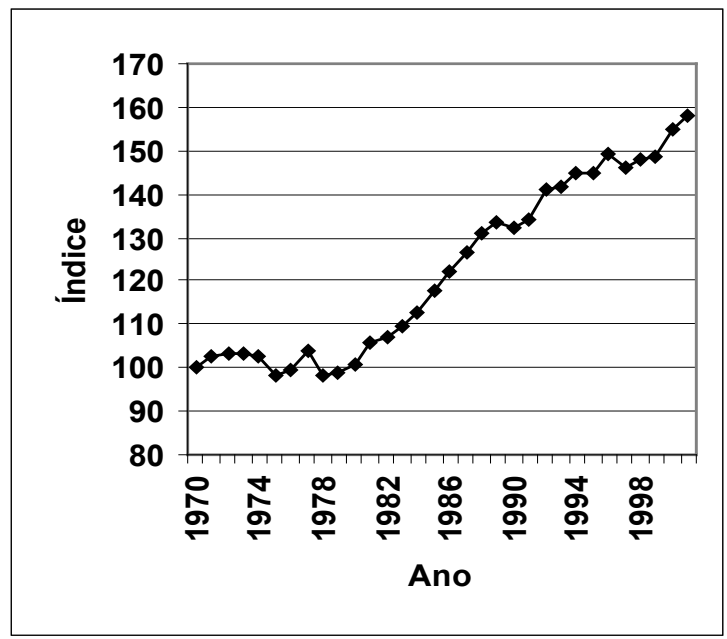

Fonte: USDA (2006)

Grande parte do crescimento da produção norte-americana de carnes no período de 1970 a 2001 ocorreu devido aos ganhos de produtividade (Figura 11). A produtividade total dos fatores (PTF) da pecuária dos EUA cresceu a uma taxa geométrica de 1,7\% ao ano no referido período, o que resultou em um crescimento de quase $58 \%$ em todo o período.

\section{- Produtividade total dos fatores e do trabalho na agropecuária dos EUA}

Esta seção apresenta e analisa a produtividade total dos fatores (PTF - terra, trabalho e capital) e do trabalho para toda a agropecuária dos EUA, sem distinguir as atividades pecuárias das agrícolas.

A produtividade total dos fatores (PTF) da agropecuária calculada pelo USDA para o período de 1970 a 2001 (Figura 12) apresentou taxa geométrica de crescimento anual de $2,2 \%$, elevando o índice de produtividade em quase $90 \%$ em todo o período avaliado. O crescimento da produtividade é favorável ao crescimento da participação da agropecuária no PIB dos EUA e ocorre no mesmo período em que diminuiu 
a relação de preços agropecuários/industriais e a relação de preços recebidos/pagos pelos agricultores (veja as figuras 4 e 5). Este fenômeno também foi ressaltado, recentemente, por Flugie et al (2007). Segundo os autores, “... o crescimento da produtividade permitiu que mais produto pudesse ser elaborado a partir da mesma quantidade de insumos, reduzindo o custo médio de produção. Os ganhos em produtividade grandemente beneficiaram a agroindústria e os consumidores na forma de preço real mais baixo ...” (Flugie et al, 2007, p. 3).

Figura 12 - Evolução da produtividade total dos fatores na agropecuária dos EUA para o período de 1970 a 2001 (base $100=1970$ )

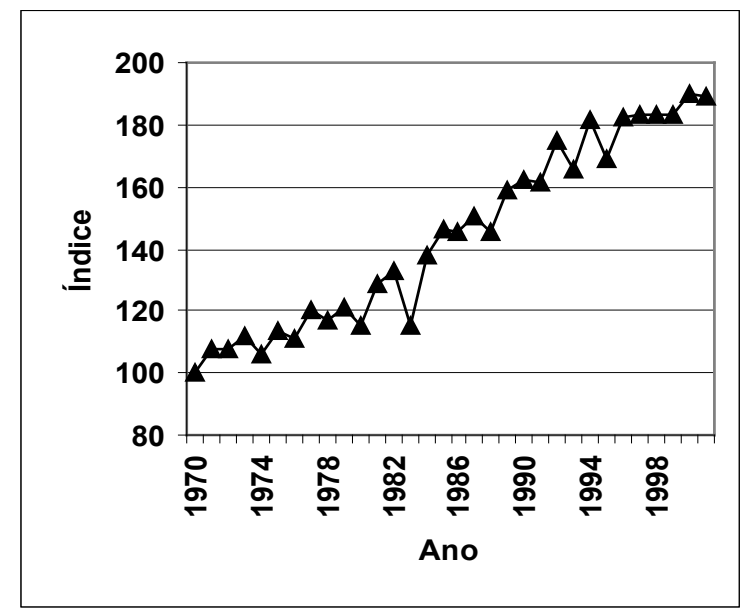

Fonte: USDA (2006)

A produtividade do trabalho na agropecuária dos EUA cresceu a um ritmo maior, a uma taxa geométrica anual de 3,7\% no período de 1970 a 2001, resultando em um crescimento acumulado de mais $200 \%$ no período como um todo (Figura 13).

Verifica-se que o crescimento da produtividade do trabalho foi sensivelmente maior que o crescimento da PTF (índice que inclui a produtividade do trabalho, da terra e do capital), implicando que a produtividade do capital e da terra, conjuntamente, cresceu menos que a produtividade total dos fatores como um todo. Este crescimento é resultado, possivelmente, do maior uso de máquinas e de insumos, 
aliado a técnicas mais eficientes de produção, que potencializaram a eficácia do trabalho.

Figura 13 - Evolução da produtividade do trabalho na agropecuária dos EUA para o período de 1970 a 2001 (base $100=1970$ )

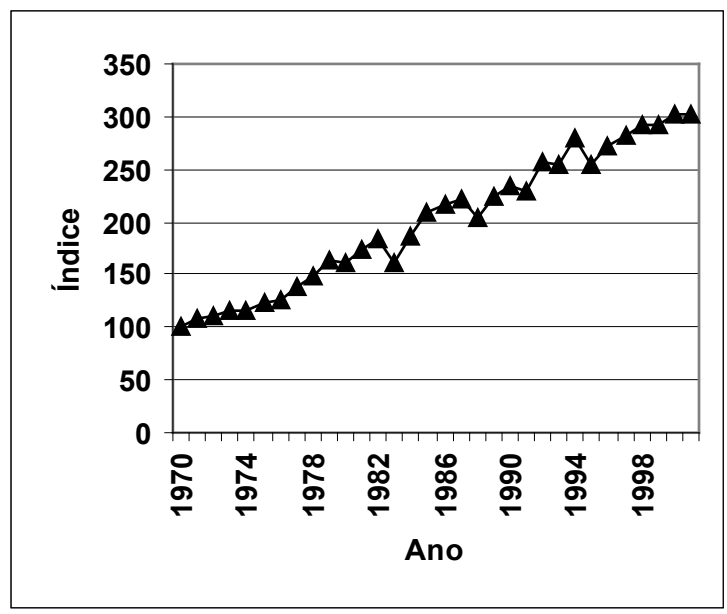

Fonte: USDA (2006)

\subsection{Produtividade no setor industrial}

Utilizam-se dados de produtividade do setor industrial como uma proxy da produtividade do setor não-agropecuário.

A Figura 14 apresenta a evolução da produtividade total dos fatores do setor industrial dos EUA para o período de 1970 a 2001. A PTF industrial obteve um crescimento anual de 1,1\% (taxa geométrica de crescimento), resultando em um crescimento acumulado de $40 \%$ ao longo de todo o período avaliado. Embora a produtividade do setor industrial tenha crescido no período, a produtividade do setor agropecuário cresceu mais aceleradamente $(2,2 \%$ a.a.).

Visto que a produtividade total dos fatores da agropecuária cresceu mais que a da atividade industrial no período de 1970 a 2001, e que esta diferença contribui para o crescimento da participação da agropecuária no PIB, resta acreditar que o comportamento decrescente dessa participação na economia dos EUA ocorre fundamentalmente 
por força dos termos de troca, que reduziram significativamente no período analisado, prejudicando o setor agropecuário. Assim, a próxima seção destina-se a analisar econometricamente os determinantes da participação decrescente da agropecuária no PIB dos EUA, revelando a intensidade de cada variável nesse processo.

Figura 14 - Evolução da produtividade total dos fatores na indústria dos EUA - 1970 a 2001 (Base $100=1970)$

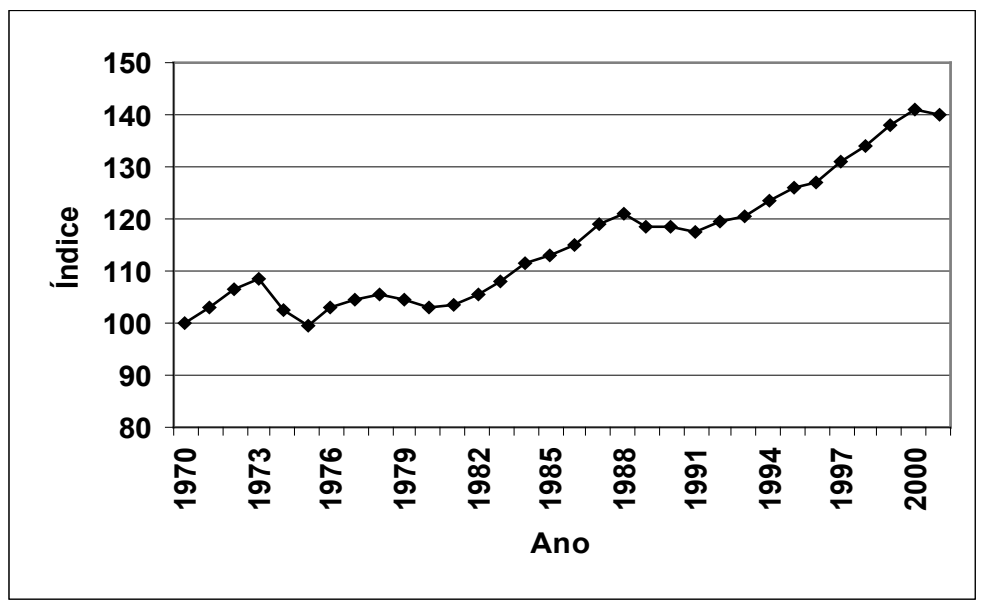

Fonte: BLS (2006)

\subsection{Análise econométrica}

O exame da Figura 1 mostra que a participação da agropecuária no PIB dos EUA decresceu de 1960 a 1970, aumentou de 1971 a 1973 e voltou a decrescer de 1973 a 2001. Para confirmar econometricamente essa "quebra" na tendência de 1971 a 1973, utiliza-se um modelo com variável binária baseado em Hoffmann e Vieira (1987) e Greene (2003). De acordo com este modelo, tem-se "quebra" de tendência se os coeficientes associados às variáveis binárias forem estatisticamente diferentes de zero. O modelo econométrico é:

$$
\mathrm{P}_{\text {agr j }}=\alpha+\beta_{1} \cdot\left(\mathrm{Ano}_{\mathrm{j}}-\mathrm{K}_{0}\right)+\mathrm{Z}_{1} \cdot \beta_{2} \cdot\left(\mathrm{Ano}_{\mathrm{j}}-\mathrm{K}_{1}\right)+\mathrm{Z}_{2} \cdot \beta_{3} \cdot\left(\mathrm{Ano}_{\mathrm{j}}-\mathrm{K}_{2}\right) \mathrm{u}_{\mathrm{j}} \text {, }
$$


Onde:

$\mathrm{P}_{\text {agr j }}=$ participação da agropecuária no PIB no ano j (j variando de 1960 a 2001);

$\alpha=$ constante;

$\mathrm{K}_{0}=$ ano antes do início da série $\left(\mathrm{K}_{0}=1959\right)$;

$\mathrm{K}_{1}$ = ano da primeira quebra (1970);

$\mathrm{K}_{2}=$ ano da segunda quebra (1973);

$$
\begin{aligned}
& Z_{1}=\left\{\begin{array}{l}
0 \text { para Ano } \leq \mathrm{K}_{1}(\text { anos de } 1960 \text { a 1970 }) \\
1 \text { para Ano }>\mathrm{K}_{1}(\text { anos de } 1971 \text { a } 2001)
\end{array}\right. \\
& Z_{2}=\left\{\begin{array}{l}
0 \text { para Ano } \leq \mathrm{K}_{2}(\text { anos de } 1960 \text { a 1973) } \\
1 \text { para Ano }>\mathrm{K}_{2}(\text { anos de } 1974 \text { a 2001) }
\end{array}\right.
\end{aligned}
$$

e;

Os dados utilizados para estimar as equações (5) e (6) encontram-se na Tabela 1 (Anexo).

O ajustamento econométrico da equação (6) foi realizado pelo método de Mínimos Quadrados Ordinários (MQO). O valor entre parênteses abaixo do coeficiente é a estatística “t” (“a” indica nível de significância inferior a $1 \%$ ).

$\operatorname{Pagr}_{j}=4,259-0,124 \cdot\left(\right.$ Ano $\left._{j}-K_{0}\right)+Z_{1} \cdot 0,459 \cdot\left(A_{j}-K_{1}\right)-Z_{2} \cdot 0,434 \cdot\left(A_{j}-K_{2}\right)$ (7)

$$
\begin{array}{ccc}
(21,81)^{\mathrm{a}} \quad(-4,46)^{\mathrm{a}} & (5,19)^{\mathrm{a}} & (-6,16)^{\mathrm{a}} \\
\mathrm{R}^{2} \text { ajustado }=0,894 \quad \mathrm{n}=42 \quad \mathrm{~F}=107,36^{\mathrm{a}} .
\end{array}
$$

Analisando a equação (7), verifica-se que o valor do teste “t” para os coeficientes de $\beta_{2}$ e $\beta_{3}$ são, respectivamente, 5,19 e -6,16, enquanto o valor " $t$ " crítico a $1 \%$ é de aproximadamente 2,86 . Portanto, rejeitam-se as hipóteses $\mathrm{H}_{0}: \beta_{2}=0$ e $\mathrm{H}_{0}: \beta_{3}=0$ em favor da hipótese alternativa, em que há "quebra” de tendência nos anos de 1971 a 1973 para a participação da agropecuária no PIB dos EUA.

Verificada estatisticamente a "quebra" de tendência, decidiu-se por estimar a equação (5) para os anos de 1973 a 2001. Inicialmente, 
analisa-se se as séries de dados da Tabela 1 são estacionárias ${ }^{6}$.

Dentre os procedimentos para determinar a ordem de integração de uma variável (ou seja, o número de raízes unitárias) tem-se os de Fuller (1976), complementados pelos de Dickev \& Fuller (1979 e 1981). De acordo com Bacchi (2005), as estatísticas $\tau_{\tau}, \tau_{\mu}$ e $\tau$ de Fuller (1976) correspondem ao teste $t$ para a estimativa do coeficiente da variável $Y_{t-1}$ da equação (8), respectivamente para os casos: (i) com constante e com tendência, (ii) apenas com constante, e (iii) sem tendência e sem constante. A seguinte equação deve ser estimada para esse teste:

$$
\Delta Y_{t}=\alpha+\beta t+\left(\sum_{i=1}^{p} p_{i}-1\right) Y_{t-1}+\sum_{i=1}^{p-1} \lambda_{i} \Delta Y_{t-i}+e_{t}
$$

onde $\lambda_{i}=-\sum_{j=i+1}^{p} \rho_{j}$, sendo $\mathrm{p}$ a ordem do modelo auto-regressivo que descreve o comportamento da série temporal.

Os testes de AIC (AKAIKE Information Criterion) e SC (SCHWARZ Criterion) em uma versão uni-equacional podem ser utilizados para a determinação do valor de p, de forma a se obter resíduos não correlacionados. Dickey \& Fuller (1979 e 1981) apresentam as distribuições para as estatísticas $\tau_{\alpha \mu}\left(\mathrm{H}_{0}: \alpha=0\right.$ no modelo que corresponde à estatística $\left.\tau_{\mu}\right), \tau_{\alpha \tau}\left(H_{0}: \alpha=0\right)$ e $\tau_{\beta \tau}\left(H_{0}: \beta=0\right)$. Os procedimentos propostos por Enders (2003) possibilitam a identificação do modelo adequado (incluindo ou não termos deterministas) para o teste de raiz unitária.

Os resultados apresentados na Tabela 2 indicam que todas as séries não possuem raiz unitária, indicando que o modelo deve ser ajustado com as séries no nível, não sendo necessário, então, realizar testes de co-integração.

Considerando os resultados abaixo (Tabela 2) e buscando obter melhores resultados econométricos, 12 equações foram estimadas pelo método dos Mínimos Quadrados Ordinários (MQO), as quais são: (1) variáveis normais (dados observados); (2) variáveis normais e ausência da variável Pagr/Pind; (3) variáveis normais e ausência das variáveis Pagr/Pind e PTFind; (4) variáveis normais e inclusão da variável PTFagr/

${ }^{6}$ Os autores agradecem a ajuda recebida da Profa. Dra. Mirian Rumenos Piedade Bacchi na elaboração da análise de co-integração. 
PTFind e exclusão da variável Pagr/Pind; (5) variáveis explicativas em LN e variável dependente em valor observado e ausência da variável Pagr/Pind; (6) variáveis explicativas em LN e variável dependente em valor observado, ausência da variável PTFind e inclusão da variável dependente defasada de 1 período como variável explicativa; (7) variáveis explicativas em LN e variável dependente em valor observado e inclusão das variáveis PTFagr/PTFind (razão das produtividades totais dos fatores nos setores agropecuário e industrial) e dependente defasada de 1 período; (8) todas as variáveis em LN, ausência das variáveis Pagr/Pind e PTFind; (9) todas as variáveis em LN, ausência das variáveis Pagr/Pind e inclusão da variável dependente defasada de 1 período como variável explicativa; (10) todas as variáveis em LN, ausência da variável Pagr/Pind e inclusão das variáveis PTFagr/PTFind e dependente defasada de 1 período como variável explicativa; (11) variáveis explicativas e defasada em LN e substituição da variável Prec/ Ppag pela variável Prec ${ }_{t} /$ Ppag ${ }_{(\mathrm{t}-1)}^{7}$; e (12) variáveis explicativas e defasada em LN, exclusão da variável PTFind e substituição da variável Prec/Ppag pela variável Prec ${ }_{\mathrm{t}} / \mathrm{Ppag}_{(\mathrm{t}-1)}$. Os resultados desses modelos encontram-se no Quadro 1 (Anexo) ${ }^{8}$.

Verifica-se que os modelos ajustados apresentam excelentes coeficientes de determinação $\left(\mathrm{R}^{2}\right)$ e $\mathrm{F}$ de alta significância estatística, revelando que as regressões são estatisticamente significantes. Porém, alguns modelos apresentam coeficientes com sinais contrários aos esperados pelo modelo de determinação da participação da agropecuária no PIB (equação (5) do item 5.1). Isto ocorre principalmente para os coeficientes das produtividades, que, em muitos casos, apresentam-se negativos para PTFagr e positivo para PTFind.

${ }^{7}$ Em função dos produtores agropecuários receberem a produção no período $t$ (preços recebidos) e adquirirem os insumos no período (t-1) (preços pagos).

${ }^{8}$ Na presença de variável dependente defasada como explicativa faz-se uso do teste $h$

de Durbin, definido pela seguinte fórmula:

$$
h \cong(1-0,5 d) \sqrt{\frac{n}{1-n[\operatorname{var}(\hat{\alpha})]}}
$$

onde $d$ é a estatística Durbin-Watson, $n$ é o número de observações e var ( $\alpha$ ) é a variância do coeficiente da variável defasada. Como o denominador da raiz pode ser um número negativo, em alguns casos a estatística h Durbin torna-se incalculável. 
Tabela 2. Resultados dos testes de raiz unitária de Dickey-Fuller para as séries utilizadas no modelo.

\begin{tabular}{cc|ccccc}
\hline Variável & Valor & \multicolumn{5}{|c}{ Estatísticas } \\
\cline { 3 - 7 } & de p & $\tau_{\beta \tau}$ & $\tau_{\tau}$ & $\tau_{\alpha \mu}$ & $\tau_{\mu}$ & $\tau$ \\
\hline Pagr(\%) & 3 & $-1,054$ & $-1,624$ & 0,862 & $-2,973$ & $-5,451^{*}$ \\
Prec/Ppag & 2 & $-3,440^{*}$ & $-3,910^{*}$ & - & - & - \\
Pagr/Pind & 1 & $-2,087$ & $-2,761$ & 1,917 & $-2,057$ & $-2,660^{*}$ \\
PTFagr & 1 & $5,245^{*}$ & $-5,406^{*}$ & - & - & - \\
PTFind & 6 & $3,528^{*}$ & $-3,525^{*}$ & - & - & - \\
\hline
\end{tabular}

Fonte: Dados da pesquisa.

*Significativo ao nível de 0,05 de probabilidade.

Analisando-se os índices de produtividade total dos fatores na agropecuária e na indústria, verificou-se alto índice de correlação entre eles $(0,934)$, o que sugeriu a exclusão da PTFind em alguns modelos ou a substituição de PTFagr e PTFind pela razão dos índices (PTFagr/PTFind). Esta última, no entanto, não foi estatisticamente significativa nas regressões em que foi incluída. As razões de preços recebidos/ preços pagos e preços agropecuários/ preços industriais também apresentaram alta correlação entre si no período de 1973 a 2001 (0,987), sugerindo também a retirada da variável Pagr/Pind da estimação (do modelo 2 em diante).

A estatística DW (Durbin-Watson), em alguns casos, também se apresentou em níveis que revelam auto-correlação positiva entre os resíduos da regressão ou região inconclusiva, revelando que certos modelos não se mostraram adequados para tal estimação. Para solucionar este problema, incorporou-se em alguns modelos a variável dependente defasada como sendo uma variável explicativa.

Os modelos que apresentam a variável Prec ${ }_{t} /$ Ppag $_{(t-1)}$ não apresentaram bons níveis de significância estatística, além de seus sinais serem ao contrário do esperado pelo modelo teórico.

Do ponto de vista econométrico, a melhor equação estimada foi o modelo 6 (reproduzido abaixo). A equação como um todo apresenta nível de significância excelente e todos os coeficientes apresentam nível de significância abaixo de $5 \%$, além dos sinais serem os esperados teoricamente pelo modelo de determinação da participação da agropecuária no PIB. 
O valor entre parênteses abaixo do coeficiente é a estatística "t" ("a” indica nível de significância inferior a $1 \%$ e "b" indica nível de significância inferior a $5 \%$ ). Abaixo da estatística " $t$ “ é apresentada a elasticidade da variável Pagr em relação à cada variável explicativa. Essas elasticidades foram calculadas com base no valor médio da variável dependente? .

Pagr $=-18,557+2,2478 \cdot \mathrm{LN}($ Prec/Ppag $)+1,904 \cdot \mathrm{LN}($ PTFagr $)+2,0171 \cdot \mathrm{LN}\left(\right.$ Pagr $\left._{\mathrm{t}-1}\right)$
$(-3,49)^{\mathrm{a}}$
$(3,89)^{\mathrm{a}}$
$(2,48)^{\mathrm{b}}$
$(4,27)^{\mathrm{a}}$

Elasticidade

0,8974

0,7599

0,8053

$\mathrm{R}^{2}=0,9461 \quad \mathrm{n}=28 \quad \mathrm{~F}=140,6^{\mathrm{a}} \quad \mathrm{h}$-Durbin $=$ Incalculável

Considerando as elasticidades, as principais variáveis determinantes da Pagr são (em ordem decrescente): Prec/Ppag, Pagr ${ }_{\mathrm{t}-1}$ e PTFagr.

Os modelos 7, 9 e 10 também se mostraram excelentes quanto à significância do teste $\mathrm{F}$ e dos coeficientes referentes à variável Prec/ Ppag, cujos sinais também se apresentaram de acordo com o modelo contábil de Bacha e Rocha (1998). Porém, embora os coeficientes das variáveis PTFagr, PTFind e PTFagr/PTFind (quando presentes no modelo) desses modelos tenham apresentado os sinais esperados, possuem baixa significância estatística.

\section{Considerações finais}

Acompanhando a tendência mundial, os EUA têm apresentado o comportamento decrescente da participação da agropecuária na composição do PIB e na geração do emprego no país.

As razões (preços recebidos versus preços pagos) e (preços

\footnotetext{
${ }_{9}^{9}$ Alternativamente, pode-se calcular as elasticidades considerando o valor ano a ano da variável dependente. Assim, surgem elasticidades ponto a ponto. Os valores das elasticidades de Pagr em relação a Prec/Ppag, PTFagr e Pagr ${ }_{t-1}$ calculadas como a média das elasticidades ponto a ponto são, respectivamente, 0,9972, 0,8446 e 0,8948. Observa-se que esses novos valores não alteram a ordem de importância das variáveis explicativas em relação aos valores das elasticidades mostradas na equação (8).
} 
agropecuários versus preços industriais) evoluíram de forma desfavorável à atividade agropecuária no período de 1970 a 2001. Não obstante, a produção de cereais nos EUA passou de 187 milhões de toneladas em 1970 para 325,5 milhões de toneladas em 2001, crescimento obtido essencialmente pelo aumento da produtividade por hectare, uma vez que a área plantada com cereais reduziu-se a partir de 1982. A produção de carnes também cresceu sensivelmente no período de 1970 a 2001, passando de menos de 20 milhões de toneladas para mais de 37 milhões de toneladas no final do período, com destaque para o desempenho da produção de carne de aves. O crescimento apresentado pela pecuária também se deve, em parte, ao crescimento da produtividade total dos fatores da atividade.

Também foi verificado o crescimento dos subsídios governamentais anualmente concedidos aos produtores agropecuários, principalmente a partir de meados da década de 1990, o que estimulou os produtores a expandirem a produção, pois esses subsídios favorecem os produtores a adotarem tecnologias modernas e, consequentemente, aumentar a produtividade dos fatores. A PTF na agropecuária dos EUA cresceu 2,2\% a.a. no período de 1970 a 2001.

A produtividade total dos fatores no setor industrial também cresceu no período de 1970 a 2001 (1,1\% a.a.), porém em menor intensidade que o crescimento ocorrido na agropecuária.

Os dados de participação da agropecuária no PIB dos EUA de 1960 a 2001 revelaram estatisticamente uma "quebra" de tendência de 1971 a 1973, motivo que influenciou a realização das estimações econométricas apenas para o período de 1973 a 2001.

O modelo econométrico ajustado com os valores das variáveis explicativas e defasada de um período em LN (variável dependente em valor observado, ou seja, modelo semi-LN) e ausência das variáveis preços relativos agropecuários/ preços industriais e produtividade total dos fatores no setor industrial (PTFind) apresentou os melhores resultados estatísticos, apresentando bons níveis de significância e os sinais dos coeficientes de acordo com os esperados pelo modelo contábil de determinação da participação da agropecuária no PIB. A regressão apontou a perda em termos de preços recebidos versus preços pagos como o fator de maior contribuição para a redução da participação da agropecuária no PIB dos EUA. 


\section{Referências}

AHUMADA, J. Teoria y programación del desarrolo economico. Santiago: Ilpes, 1967. 62 p.

ALEXANDRATOS, N. World food and agriculture: outlook for the medium and longer term. Proceedings of the National Academy of Sciences, USA. v. 96, p. 5908-6914, Maio 1999. Disponível em: < http:// www.pnas.org/cgi/content/full/96/11/5908 > . Acesso em: 4 out. 2006.

ALVES, A.F. Contribuição da agricultura ao crescimento econômico: o excedente financeiro de 1980 a 1998. Piracicaba, ESALQ/USP, 2000. 127 p. ARAÚJO, P.F.C. Agricultura no processo de desenvolvimento econômico. In: ARAÚJO, P.F.C.; SCHUH, G. E. Desenvolvimento da agricultura. São Paulo: Editora Pioneira, 1975. v. 1, p. 83-97.

ARAÚJO, P.F.C.; SCHUH, G.E. Desenvolvimento econômico e agricultura. In: BARROS, G.S; AMARAL, C.M.; ARAÚJO, P.F.C. de; SCHUH, G.E.. Fundamentos de economia agrícola. Piracicaba: FEALQ, fev. 1988, p. 227-277.

BACHA, C.J.C. Economia e política agrícola no Brasil. São Paulo: Atlas, 2004. 226 p.

BACHA, C.J.C.; ROCHA, M.T. O comportamento da agropecuária brasileira no período de 1987 a 1996. Revista de Economia e Sociologia Rural, Brasília. v. 36, n. 1, p. 35-59, jan./mar. 1998.

BACCHI, M. R. P. Formação de preços no setor sucroalcooleiro da Região Centro-Sul do Brasil: relação com o mercado de combustível fóssil. In: Encontro Nacional de Economia, 33, 2005. Anais... Associação Nacional de Centros de Pós-Graduação em Economia, 2005, 1 CD-ROM.

BARROS, A.L.M. de. Capital, produtividade e crescimento da agricultura: o Brasil de 1970 a 1995. 1999, 149 p. Tese (Doutorado em Ciências Econômicas) - Escola Superior de Agricultura "Luiz de Queiroz", Universidade de São Paulo, Piracicaba, 1999.

BONELLI, R. Produtividade total dos fatores (PTF) e o produto potencial da economia brasileira: uma nota. São Paulo, IPEA. 2001. 2 p. (Boletim Conjuntural, 53) 
BONELLI, R. Industrialização e desenvolvimento: notas e conjecturas com foco na experiência do Brasil. Disponível em: < http:// www.ecostrat.com.br > . Acesso em: 10 dez. 2005.

BRUGNARO, R.; BACHA, C.J.C.. Analysis of increased participation of agriculture in the Brazilian GDP from 1994 a 2004. In: CONGRESS OF THE EUROPEAN REGIONAL SCIENCE ASSOCIATION, 46., 2006. Congress programme, Volos: ERSA. Paper n. 758, p.19. Disponível em: < http://www.ersa.org > . Acesso em: 14 set. 2006.

BUREAU OF LABOR STATISTICS - BLS. Disponível em: < http://www. bls.gov. > Acesso em: 27 jun. 2006.

DICKEY, D.A.; FULLER, W.A. Distribution of the estimator for autoregressive time series with a unit root. Journal of the American Statistical Association, v. 74, p. 427-431, 1979.

DICKEY, D.A.; FULLER, W.A. Likelihood ratio statistics for auto-regressive time series with a unit root. Econometrica, v. 49, p. 1057-1072, 1981.

ENDERS. W. Applied Econometric Time Series. 2nd ed. New Jersey: John Wiley \& Sons, 2003. 480p.

ERS Agricultural Income and Finance Situation and Outlook, Economic Research Service, U.S. Department of Agriculture. Disponível em http://usda.mannlib.cornell.edu/MannUsda/viewDocumentInfo. do?documentID = 1254 (acessado em 24/09/07).

FUGLIE, K.O.; MAcDONALD, J.M.; BALL, E. Productivity Growth in U.S. Agriculture, United States Department of Agriculture, Economic Research Service, Economic Brief number 9, setembro de 2007 (disponível em http://www.ers.usda.gov/publications/EB9/eb9.pdf, acessado em 19/09/07).

FULLER, W.A. Introduction to statistical time series. New York: John Wiley \& Sons, 1976. 480p.

FURTUOSO, M.C.O.; GUILHOTO, J.J.M. Estimativa e mensuração do produto interno bruto do agronegócio, 1994 a 2000. Revista de Economia e Sociologia Rural, Brasília, v. 41, n. 4, p. 803-827, out./dez. 2003. Disponível em: < http:// www.scielo.br > . Acesso em: 10 dez. 2005. 
GASQUES, J.G.; BASTOS, E.T.; BACCHI, M.R.P.; CONCEIÇÃO, J.C.P.R. da. Condicionantes da produtividade da agropecuária brasileira. Brasília: IPEA, 2004. 31 p. (Texto para discussão, 1017).

GOLLIN, D.; PARENTE, S.; ROGERSON, R. The role of agriculture in development. Washington, USDA. 2000. Disponível em: < http:// www.nass.usda.gov > . Acesso em: 20 mar. 2006.

GREENE, W.H. Econometric Analysis, 5. ed. Upper Saddle River: Prentice Hall, 2003. 1026 p.

GUILHOTO, J.J.M. Regional importance of the agribusiness in the brazilian economy. In: CONGRESS OF THE EUROPEAN REGIONAL SCIENCE ASSOCIATION, 44., Porto. 2004. 1 CD-ROM.

HOFFMANN, R.; VIEIRA, S. Análise de regressão, uma introdução à econometria. São Paulo: HUCITEC, 1987. 378 p.

ORGANIZAÇÃO PARA COOPERAÇÃO ECONÔMICA E DESENVOLVIMENTO - Producer Support Stimate, 2006. Disponível em: < http:// www.oecd.org > . Acesso em: 20 jun. 2006.

REGUNAGA, M. Issues in agricultural trade: the Américas. Disponível em: < http://www.agritrade.org > . Acesso em: 18 nov. 2005.

ROSSI JÚNIOR, J.L.; FERREIRA, P.C. Evolução da produtividade industrial brasileira e abertura comercial. Rio de Janeiro: IPEA, 1999, 31 p. (Texto para discussão, 651).

RUTTAN, V.W. Productivity Growth in World Agriculture: Sources and Constraints In Journal of Economic Perspectives, vol. 16, número 4, p. 161 a $184,2002$.

SCHUH, G.E. A agricultura no Brasil: política, modernização e desenvolvimento econômico. Revista de Política Agrícola, Brasília, v. 6, n. 2, p. 15-21, abr./maio/jun. 1997.

SCHULTZ, T.W. The declining economic importance of agricultural land. The Economic Journal, London, v. 61, n. 244, p. 725-740, dez. 1951. Disponível em: < http://www.jstor.org > . Acesso em: 15 nov. 2005.

STERN, N. Growth theories, old and new, and the role of agricul- 
ture in economic development. London: Suntory-Toyota International Centre for Economic and Related Disciplines/London School of Economics, 1994. $148 \mathrm{p}$.

UNITED STATES DEPARTMENT OF AGRICULTURE - USDA. Sistema NASS. Disponível em: < http://www.nass.usda.gov > Acesso em: 25 mai. 2006.

WESTCOTT, P.C.; PRICE, J.M. Analysis of the U.S commodity loan program with marketing loan. Washington, USDA. 2001. 22 p (Agricultural Economic Report n. 801). Disponível em: < http://www.usda. gov > . Acesso em: 16 jun. 2006.

WOLD BANK. World development indicators. 2000. CD-ROM WOLD BANK. World development indicators. 2005. CD-ROM 
Anexo

Tabela 1 - Dados utilizados nas regressões dos EUA

\begin{tabular}{|c|c|c|c|c|c|}
\hline Ano & Pagr(\%) & Prec/Ppag & Pagr/Pind & PTFagr & PTFind \\
\hline 1960 & 4,22 & - & - & - & - \\
\hline 1961 & 4,16 & - & - & - & - \\
\hline 1962 & 3,93 & - & - & - & - \\
\hline 1963 & 3,76 & - & - & - & - \\
\hline 1964 & 3,38 & - & - & - & - \\
\hline 1965 & 3,51 & - & - & - & - \\
\hline 1966 & 3,36 & - & - & - & - \\
\hline 1967 & 3,12 & - & - & - & - \\
\hline 1968 & 2,95 & - & - & - & - \\
\hline 1969 & 3,04 & - & - & - & - \\
\hline 1970 & 3,01 & 100,00 & 100,00 & 100,00 & 100,00 \\
\hline 1971 & 3,51 & 97,94 & 98,37 & 108,05 & 102,79 \\
\hline 1972 & 3,69 & 102,68 & 106,90 & 108,11 & 106,60 \\
\hline 1973 & 4,84 & 126,92 & 144,19 & 111,56 & 108,38 \\
\hline 1974 & 4,33 & 120,18 & 131,32 & 106,12 & 102,54 \\
\hline 1975 & 4,07 & 105,30 & 118,28 & 113,95 & 99,62 \\
\hline 1976 & 3,57 & 99,06 & 113,94 & 111,41 & 103,17 \\
\hline 1977 & 3,23 & 92,47 & 107,08 & 120,23 & 104,57 \\
\hline 1978 & 3,32 & 98,06 & 110,44 & 116,58 & 105,46 \\
\hline 1979 & 3,49 & 98,97 & 110,73 & 121,36 & 104,70 \\
\hline 1980 & 2,90 & 90,30 & 96,47 & 115,11 & 103,05 \\
\hline 1981 & 3,15 & 85,27 & 89,49 & 128,78 & 103,68 \\
\hline 1982 & 2,88 & 79,28 & 81,74 & 133,04 & 105,33 \\
\hline 1983 & 2,15 & 77,54 & 82,66 & 115,57 & 107,99 \\
\hline 1984 & 2,57 & 80,28 & 84,35 & 137,64 & 111,29 \\
\hline 1985 & 2,41 & 72,76 & 75,22 & 146,56 & 113,20 \\
\hline 1986 & 2,22 & 71,56 & 77,06 & 145,52 & 115,10 \\
\hline 1987 & 2,24 & 72,60 & 77,49 & 150,37 & 118,78 \\
\hline 1988 & 2,04 & 75,26 & 83,12 & 145,27 & 120,94 \\
\hline 1989 & 2,10 & 76,91 & 83,22 & 158,83 & 118,65 \\
\hline 1990 & 2,06 & 74,93 & 79,57 & 162,43 & 118,40 \\
\hline 1991 & 1,89 & 71,43 & 72,76 & 161,62 & 117,26 \\
\hline 1992 & 1,95 & 67,33 & 70,07 & 175,03 & 119,29 \\
\hline 1993 & 1,86 & 66,06 & 71,91 & 165,97 & 120,69 \\
\hline 1994 & 1,83 & 63,41 & 71,44 & 181,88 & 123,48 \\
\hline 1995 & 1,61 & 63,42 & 70,79 & 169,23 & 125,89 \\
\hline 1996 & 1,80 & 66,00 & 78,35 & 182,60 & 126,90 \\
\hline 1997 & 1,69 & 60,05 & 71,94 & 183,00 & 130,84 \\
\hline 1998 & 1,63 & 58,51 & 67,57 & 183,00 & 134,14 \\
\hline 1999 & 1,62 & 55,13 & 61,59 & 182,83 & 137,94 \\
\hline 2000 & 1,61 & 53,44 & 54,75 & 189,84 & 141,24 \\
\hline 2001 & 1,60 & 55,10 & 59,99 & 189,23 & 139,97 \\
\hline
\end{tabular}

Fonte: World Bank (2000, 2005), USDA (2006) e BLS (2006)

Nota: Pagr = participação da agropecuária no PIB em \%; Prec/Ppag = índice da relação de preços recebidos/preços pagos pelo setor agropecuário (base $100=1970$ ); Pagr $/$ Pind = índice da relação de preços agropecuários/ preços industriais (base $100=1970$ ); PTFagr = índice da produtividade total dos fatores no setor agropecuário (base $100=1970$ ); ePTFind $=$ índice da produtividade total dos fatores no setor Industrial (base $100=1970$ ). 
Quadro 1 - Resultados dos modelos econométricos ajustados para os EUA no período de 1973 a $2001^{10}$

\begin{tabular}{|c|c|c|c|c|c|c|c|c|c|c|c|c|c|}
\hline Modelo & & Const. & Prec/Ppag & $\begin{array}{l}\text { Prec }_{t} / \\
\text { Ppag }_{(t-1)}\end{array}$ & Pagr/Pind & PTFagr & PTFind & $\begin{array}{l}\text { PTFagr/ } \\
\text { PTFind }\end{array}$ & $\operatorname{Pagr}_{(t-1)}$ & Estat. F & $\mathrm{R}^{2}$ & $\begin{array}{l}\text { Estat. } \\
\text { DW }\end{array}$ & $\begin{array}{c}\mathrm{h} \text { de } \\
\text { Durbin }\end{array}$ \\
\hline & Coef. & $-1,3281$ & 0,0461 & & 0,000841 & $-0,00033$ & 0,00158 & & & 117,9 & & & \\
\hline 1. Variáveis normais & Probab. & 0,2399 & 0,0126 & & 0,9485 & 0,9476 & 0,8706 & & & 0,000 & 0,952 & 1,357 & - \\
\hline \multirow{2}{*}{$\begin{array}{l}\text { 2. Variáveis normais e } \\
\text { exclusão da var. } \\
\text { Pagr/Pind }\end{array}$} & Coef. & $-1,3615$ & 0,0472 & & & $-0,00031$ & 0,00175 & & & 163,8 & \multirow[b]{2}{*}{0,952} & \multirow[b]{2}{*}{1,3562} & \multirow[b]{2}{*}{ - } \\
\hline & Probab. & 0,1669 & 0,0000 & & & 0,9492 & 0,8491 & & & 0,000 & & & \\
\hline \multirow{2}{*}{$\begin{array}{l}\text { 3. Variáaeis normais e } \\
\text { ausência das var. } \\
\text { Pagr/Pind e PTFind }\end{array}$} & Coef. & $-1,2654$ & 0,0472 & & & 0,000402 & & & & 255,1 & \multirow[b]{2}{*}{0,952} & \multirow[b]{2}{*}{1,2960} & \multirow[b]{2}{*}{-} \\
\hline & Probab. & 0,1258 & 0,000 & & & 0,8972 & & & & 0,000 & & & \\
\hline \multirow{2}{*}{$\begin{array}{l}\text { 4. Variáveis normais e } \\
\text { inclusão da var. } \\
\text { PTFagr/PTFind }\end{array}$} & Coef. & $-1,0415$ & 0,0463 & & & & & $-0,0708$ & & 255,1 & \multirow[b]{2}{*}{0,952} & \multirow[b]{2}{*}{1,367} & \multirow[b]{2}{*}{-- } \\
\hline & Probab. & 0,2844 & 0,000 & & & & & 0,8977 & & 0,000 & & & \\
\hline \multirow{2}{*}{$\begin{array}{l}\text { 5. Variáveis } \\
\text { explicativas em } L N \text { e } \\
\text { var. dependente em } \\
\text { valor observado } \\
\end{array}$} & Coef. & $-22,9302$ & 4,1911 & & & $-0,5854$ & 2,1397 & & & 105,2 & \multirow[b]{2}{*}{0,927} & \multirow[b]{2}{*}{1,209} & \multirow[b]{2}{*}{-} \\
\hline & Probab. & 0,0041 & 0,000 & & & 0,4997 & 0,1189 & & & 0,000 & & & \\
\hline \multirow{2}{*}{$\begin{array}{l}\text { 6. Variáveis } \\
\text { explicativas em LN, } \\
\text { exclusão da var. } \\
\text { PTFind, e inclusão da } \\
\text { var. dependente } \\
\text { defasada como } \\
\text { explicativa } \\
\end{array}$} & Coef. & $-18,5574$ & 2,2478 & & & 1,9035 & & & 2,0171 & 140,6 & \multirow[b]{2}{*}{0,946} & & \multirow[b]{2}{*}{$\begin{array}{c}\text { Incalcu- } \\
\text { lável }\end{array}$} \\
\hline & Probab. & 0,0019 & 0,001 & & & 0,0204 & & & 0,0003 & 0,000 & & 1,628 & \\
\hline \multirow{2}{*}{$\begin{array}{l}\text { 7. Variáveis } \\
\text { explicativas em LN e } \\
\text { inclusão das Var. } \\
\text { PTFagr/PTFind e } \\
\text { dependente defasada } \\
\text { como explicativa }\end{array}$} & Coef. & $-6,663$ & 1,7585 & & & & & 0,8384 & 1,4734 & 115,0 & \multirow[b]{2}{*}{0,935} & \multirow[b]{2}{*}{1.515} & \multirow[b]{2}{*}{$\begin{array}{c}\begin{array}{c}\text { Incalcu- } \\
\text { lável }\end{array} \\
\end{array}$} \\
\hline & Probab. & 0,0078 & 0,0075 & & & & & 0,333 & 0,0037 & 0,000 & & & \\
\hline \multirow{2}{*}{$\begin{array}{l}\text { 8. Todas as variáveis } \\
\text { em LN, exclusão das } \\
\text { var. Pagr/Pind e } \\
\text { PTFind }\end{array}$} & Coef. & $-3,239$ & 1,2208 & & & $-0,2397$ & & & & 214,1 & \multirow[b]{2}{*}{0,943} & \multirow[b]{2}{*}{1,574} & \\
\hline & Probab. & 0,0934 & 0,000 & & & 0,2817 & & & & 0,000 & & & -- \\
\hline \multirow{2}{*}{$\begin{array}{l}\text { 9. Todas as variáveis } \\
\text { em LN, exclusão da } \\
\text { var. Pagr/Pind e } \\
\text { inclusão da var. } \\
\text { dependente defasada } \\
\text { como explicativa }\end{array}$} & Coef. & $-3,8763$ & 0,8031 & & & 0,3886 & $-0,2487$ & & 0,5563 & 117,9 & \multirow[b]{2}{*}{0,954} & \multirow[b]{2}{*}{1,933} & \\
\hline & Probab. & 0,1719 & 0,0021 & & & 0,2086 & 0,5706 & & 0,0038 & 0,000 & & & 0,438 \\
\hline \multirow{2}{*}{$\begin{array}{l}\text { 10. Todas as variáveis } \\
\text { em LN, exclusaro da } \\
\text { var. Pagr/Pind e } \\
\text { inclusão das var. } \\
\text { PTFagr/PTFind e } \\
\text { dependente defasada } \\
\text { como explicativa }\end{array}$} & Coef. & $-3,01622$ & 0,7652 & & & & & 0,3553 & 0,5296 & 163,3 & & & \\
\hline & Probab. & 0,0005 & 0,0007 & & & & & 0,2121 & 0,0017 & 0,000 & 0,953 & 1,935 & 0,283 \\
\hline $\begin{array}{l}\text { 11. Variáveis } \\
\text { explicativas em LN e }\end{array}$ & Coef. & $-2,0703$ & & $-0,1406$ & & 1,088 & $-0,5631$ & & 2,7161 & 60,14 & & & \\
\hline $\begin{array}{l}\text { utilização da var. Prect } \\
\text { /Ppag }\end{array}$ & Probab. & 0,8306 & & 0,8769 & & 0,3461 & 0,6908 & & 0,0012 & 0,000 & 0,913 & 2,546 & $\begin{array}{c}\text { Incalcu- } \\
\text { lável }\end{array}$ \\
\hline $\begin{array}{l}\text { 12. Variáveis } \\
\text { explicativas em LN, } \\
\text { exclusão da var. }\end{array}$ & Coef. & $-3,941$ & & $-0,1264$ & & 0,902 & & & 2,7799 & 83,03 & & & \\
\hline $\begin{array}{l}\text { PTFind e utilização da } \\
\text { var. Prec / Ppag(t-1) }\end{array}$ & Probab. & 0,6359 & & 0,8872 & & 0,3827 & & & 0,0006 & 0,000 & 0,912 & 2,675 & $\begin{array}{l}\text { Incalcu- } \\
\text { lável }\end{array}$ \\
\hline
\end{tabular}

Fonte: Resultados da pesquisa

${ }^{10}$ Os modelos 5, 6, 7, 11 e 12 utilizam a variável dependente em valor observado. No caso de haver a variável dependente defasada como explicativa, esta se encontra em LN. 